ARCHIVO ESPAÑOL DE ARTE, LXXIX, 313

ENERO-MARZO, pp. 23-42, 2006

ISSN: 0004-0428

\title{
LAS CASAS DE LA FAMILIA BAZÁN EN GRANADA
}

\author{
POR \\ ROSA LÓPEZ TORRIJOS \\ Universidad de Alcalá ${ }^{1}$
}

Nueva documentación, procedente del Archivo de los Marqueses de Santa Cruz, permite reconstruir la historia de las primeras casas del linaje Bazán en Granada, desde el siglo XV hasta el XIX en que fueron demolidas. Se rectifican o precisan confusas y, en ocasiones, erróneas noticias recogidas por estudiosos anteriores. La importancia de esta casa viene dada por ser una de las primeras que reciben obras y artífices genoveses en España pagados por Don Álvaro de Bazán, padre del futuro marqués de Santa Cruz que contrataría, igualmente, con artistas genoveses la construcción y decoración de su palacio en El Viso (Ciudad Real).

Palabras clave: Arte genovés. Siglo XVI. Álvaro de Bazán. Gio Giacomo y Guglielmo della Porta. Gio Pietro de Pasallo. Nicola de Corte. Antonio Semino. Granada. El Viso

New documentation from the Archive of the Marqueses of Santa Cruz permits the reconstruction of the history of the first residences of the Bazán family in Granada, from the fifteenth through the nineteenth centuries, when they were demolished. Now it is possible to rectify and clarify confused and sometimes erroneous information gathered by previous scholars. This house is important because it is one of the first in Spain to receive Genoese artists and artworks, paid by Álvaro de Bazán, father of the future marquis of Santa Cruz, who in turn would contract Genoese artists for the construction and decoration of his palace in El Viso (Ciudad Real).

Key words: Genoese art. Sixteenth century. Álvaro de Bazán. Gio Giacomo and Guglielmo della Porta. Gio Pietro de Pasallo. Nicola de Corte. Antonio Semino. Granada. El Viso.

Como hemos tratatado en un trabajo anterior sobre los Bazanes de Granada y su primera fundación en la ciudad ${ }^{2}$, el primer miembro de la familia establecido en la recién conquistada Granada fue don Alvaro de Bazán, Comendador de Castroverde, abuelo del que será primer marqués de Santa Cruz. Este primer Alvaro participó muy activamente en las campañas contra los musulmanes

\footnotetext{
${ }^{1}$ Este trabajo forma parte de un proyecto de investigación financiado por la DGESIC (PB98-0708).

${ }^{2}$ López Torrijos, Rosa : "Los Bazanes de Granada y el monasterio de Sancti Spiritus" (en prensa)
} 
del reino de Granada y consiguió por ello honores y posesiones que determinarían el establecimiento de la familia en la antigua capital del reino musulmán donde él había ido adquiriendo posesiones antes de 1492. A partir de ellas iría configurando lo que sería la primera casa principal de su linaje, casa que su hijo pretendió renovar drásticamente y que perdería toda su importancia al trasladarse la familia a la sede de su nuevo señorío del Viso y Santa Cruz.

Las casas de los Bazán en Granada, conservadas hasta el siglo XIX, constituyen, como se recordará, uno de los ejemplos más tempranos de llegada de obras y artífices genoveses a España en el siglo XVI. Sobre ellas existen algunos estudios y diversas noticias interesantes y confusas que ahora pretendemos aclarar, a partir de nuevos datos procedentes principalmente del archivo histórico de la familia y de la revisión de documentos y de estudios publicados hace tiempo y a los que iremos haciendo referencia a lo largo de este trabajo.

El primer Alvaro de Bazán establecido en Granada funda un mayorazgo poco antes de morir y en su testamento señala primeramente "por bienes de mayorazgo las casas de Granada con sus tiendas y mesones y horno"; en aquellos momentos una serie de inmuebles urbanos que él había ido comprando sucesivamente y cuya trayectoria podemos reconstruir documentalmente.

La primera adquisición que realiza don Alvaro en la ciudad de Granada corresponde al año 1464 (869 de la Hégira) y se refiere a un baño comprado a Omar Ben Josef por 23 onzas de oro. En 1472 adquire a otro musulmán una casa de mesón o baño en la calle Lavanderos.

En 1491 compra dos casas a musulmanes y una al cristiano portugués Hernando Fonseca ${ }^{3}$, las tres en el barrio de los Hilanderos, y allí mismo sigue comprando bienes después de la conquista, aprovechando sin duda las ventas de aquellos musulmanes que quieren abandonar la ciudad. En 1492 compra una casa y una casa mesón, ambas en la calle de Hilanderos y en 1497 una huerta en la misma calle, a un musulmán también.

Además de ésto, en 1492 compra don Alvaro una casa de mesón en lo alto del puente de Ben Rasic, en la calle de Polleros n⿳0 10, y ese mismo año a Fátima, hija del rey Abu Abdalah Algaleb Billa (Boabdil), un horno, junto al mismo puente de Ben Rasic 4 .

De todos estos bienes, los adquiridos en el barrio de los Hilanderos -que debían de ser pequeñas fincas colindantes o próximas con las que se buscaba una posesión de grandes dimensiones - constituyen el origen de la casa solariega de los Bazán en Granada.

Aunque no es fácil confirmar los datos de la Granada musulmana, sí podemos recordar que la casa de los Bazán estaba situada junto a un puente de época nazarí llamado Algharrazin (o de los Zapateros), que cambió su nombre por el "de la gallinería" después de la conquista y más tarde por el de San Francisco, por estar situado cerca del convento de ese nombre ${ }^{5}$. Esto indica su proximidad a la Zapatería y una huella de ambos oficios -zapateros e hilanderos- y de las posesiones de don Alvaro se puede ver en la relación de los hábices de la ciudad de Granada de 1505, donde se registra, en la colación de Santa María de la O, "en la calle que ba del Hatavín a Santa Ana" una tienda "antes de don Albaro de Bazán [...] está en ella Martín Aldabrí, zapatero"; junto a ella hay otra tienda "donde hazen las ruecas"6.

\footnotetext{
3 Archivo de los Marqueses de Santa Cruz, leg. $1 \mathrm{n}^{\circ} 9$

${ }^{4}$ Recuérdese que los hornos en Granada eran de los emires aunque algunos habían sido vendidos a particulares. Precisamente fue Abul Hasan Alí, el padre de Boabdil, quien inició la política reivindicatoria de tales bienes (Ladero Quesada, M.A., Granada después de la conquista: repobladores y mudéjares, Granada, Diputación Provincial de Granada, 1993, p.312).

5 Es el gran convento de San Francisco al que se trasladó parte de la comunidad en 1507 cuando les fue cedida la primitiva iglesia mayor de Santa María, edificada nada más conquistar la ciudad. Véase Barrios Rozua, Juan Manuel: Guía de la Granada desaparecida, Albolote (Granada), Editorial Comares, 1999, p.294.

6 Villanueva Rico, $\mathrm{M}^{\mathrm{a}}$ del Carmen. Hábices de las mezquitas de la ciudad de Granada y sus alquerías. Edición, introducción e índices por... Madrid, Instituto hispano-árabe de cultura, 1961, p. 37
} 
En 1527 el mayor número de tejedores e hiladores seguía viviendo aún en el barrio de la iglesia de Santa Ana, situada detrás de las casas de Bazán ${ }^{7}$ lo que puede ser resto testimonial de la existencia de hilanderos en época musulmana.

Como hemos visto anteriormente, cuando don Alvaro funda su mayorazgo, en 1497, cita sus casas con tiendas, mesones, y horno", además de la huerta recién comprada, es decir, básicamente los immuebles que había adquirido de musulmanes; lo mismo sucede en su testamento de 1499 , por lo que su actuación en estas propiedades debió limitarse a acondicionar, o reformar, algunas de las casas para constituir en ella su "Casa Principal".

Documentos, noticias, descripciones y relatos de viajeros nos sirven para conocer el aspecto de Granada en los primeros años después de su conquista. La belleza del sitio, la excepcionalidad de sus palacios y la singularidad de sus costumbres, unido a la facilidad de observación que daba el dominio cristiano, atrajeron la atención general hacia esta ciudad largo tiempo anhelada, constantemente elogiada y para siempre mitificada.

Sin embargo, los testimonios primeros nos hablan también de una ciudad en gran parte abandonada por los numerosos musulmanes huidos al campo o a ciudades del norte de Africa, muy poco tiempo después de la conquista. En ella abundaban las casas vacías, dejadas apresuradamente por los musulmanes y compradas ventajosamente por los cristianos, los cuales acumulaban propiedades, la mayor parte de las veces deshabitadas y desatendidas y cuyos materiales útiles eran aprovechados por nuevos vecinos no tan afortunados.

Don Alvaro tenía en Granada tres tipos de propiedad muy representativos de lo que era la antigua ciudad sarracena: viviendas (casas), locales comerciales-industriales (tiendas, mesones y horno) y huerta.

Para conocer mejor estas propiedades recordemos que la casa musulmana popular era muy pequeña, al decir de los $\operatorname{cristianos}^{8}$, aun en el caso de que su propietario tuviese una cierta categoría solía constar de dos pisos y estaba coronada por una azotea o más frecuentemente por una torre, en muchos casos abierta por varios lados, que servía de mirador. El centro de la casa era el patio al que se accedía por un portal que tenía anejo un establo. En la planta baja había una gran sala abierta al patio en la que se vivía en verano, y debajo de la escalera estaba el aljibe y a veces una despensa. También se situaban en la planta baja las "necesarias", que llamaron la atención de los cristianos. Muy frecuentemente carecían de cocina porque se guisaba en hornillos portátiles, en el patio o en otro lugar, y se recurría a los hornos públicos para las grandes necesidades. En el piso superior estaban las habitaciones principales abiertas a los corredores del patio y a veces este piso no ocupaba toda la extensión de la planta baja o, por el contrario, se continuaba sobre el piso bajo de una casa contigua. Y como es sabido no tenía huecos a la calle o se abrían solo en los pisos altos y estaban ocultos por celosías o ajimeces ${ }^{9}$.

Como las casas musulmanas resultaban sumamente pequeñas para los cristianos era frecuente que éstos comprasen varias para unirlas y edificar una nueva vivienda al uso castellano, aunque conservando algunos recuerdos de la casa árabe.

\footnotetext{
7 Véase Villanueva Rico, Mª del Carmen: Casas, mezquitas y tiendas de los habices de las iglesias de Granada, Edición, introducción e índices por..., Madrid, 1966, Instituto Hispano-árabe de Cultura, 1966 p.48ss.

${ }^{8}$ Recuérdese el comentario de Münzer en su visita a Granada: "Las casas de los sarracenos son en su mayoría tan reducidas -con pequeñas habitaciones, sucias en el exterior, muy limpias interiormente-, que apenas es creíble [...] En tierra de cristianos una casa ocupa más espacio que cuatro o cinco casas de sarracenos. Por dentro son tan intrincadas y revueltas que las creerías nidos de golondrinas." (Münzer, Jerónimo: Viaje por España y Portugal (1494-1495), ed. Madrid, Polifemo, 1991 pp.109-111). Obsérvese también la mentalidad renacentista que, frente a la no planificación de la casa musulmana la juzga "intrincada y revuelta".

${ }^{9}$ Estas características las da Villanueva (ob.cit.1966) que construye el modelo con los datos tomados de las casas musulmanas registradas después de la conquista.
} 
Como hemos dicho anteriormente -y como veremos más adelante- por los datos que tenemos de la familia Bazán en estos años, su primera residencia en Granada debió ser una de estas casas compradas a los musulmanes, tal vez reformada para los nuevos usos, pero no edificada de nueva planta.

El segundo tipo de propiedad adquirida por don Alvaro correspondía a tiendas, mesón y horno.

Granada, como ciudad muy poblada y comercial disponía de un gran número de tiendas, al margen de los zocos característicos del mundo musulmán. Las tiendas eran muy pequeñas también; en ellas se vendían -y a veces se fabricaban- los productos y eran independientes de las viviendas. Generalmente constaban de un único espacio en la planta baja de los edificios, comunicado con la calle por una puerta que, abierta, les servía de techo o cobertizo. En casos más raros tenía una cámara pequeña, especie de trastienda o vivienda del vigilante ${ }^{10}$.

Recordemos que los lugares más comerciales de Granada eran el Zacatín y la calle Elvira seguidos de las orillas del Darro. El Zacatín, que terminaba en el cruce con la calle Elvira, pasaba justamente junto al puente de la Gallinería sobre el río Darro, en la orilla opuesta a las casas de los Bazán, lo que justifica la existencia desde tiempos musulmanes de las tiendas compradas por don Alvaro. Algunas de ellas estaban situadas en la planta baja de las casas adquiridas primero, como era habitual ${ }^{11}$ y es muy probable también que el comendador las utilizase como tales, alquilándolas a moriscos o cristianos para obtener una renta. De hecho, y como comprobaremos más tarde, estos locales comerciales siguieron siendo habituales en las casas familiares de Granada hasta épocas muy modernas.

Otro tipo de establecimiento que se cita en estas primeras casas de Bazán son los mesones y el horno.

Más arriba hemos visto como don Alvaro adquiría de musulmanes una casa de mesón o baño, dos casas de mesón y un horno, es decir, casas utilizadas como establecimientos públicos ${ }^{12}$. Los mesones y los hornos estaban estrechamente relacionados en la Granada musulmana ya que los hornos públicos se utilizaban, además de para fabricar distintas clases de pan y dulces, para guisar comidas que se servían en los mesones. Así pues, los mesones y el horno adquiridos por don Alvaro pudieron ser también, una fuente de ingresos para la familia.

Recuérdese que los hornos en Granada eran privativos de los emires aunque algunos se habían vendido a particulares -don Alvaro por ejemplo, se lo había comprado a una hija de Boabdil- y después de la conquista formaron parte de las mercedes reales concedidas en pago a servicios distinguidos. Precisamente una noticia marginal nos sirve para conocer el uso que se les daba, la categoría del propietario y la importancia de la zona.

A finales del siglo XV, para la construcción de la alhóndiga llamada Zaida se permutan a los musulmanes las llamadas casas de Haquen por la antigua Casa de la Justicia y de ésta se dice que está "çerca del Darro e a por linderos de la vna parte un horno de haser pasteles que es del corregidor que sale al çacatin en frente de la calle nueva que sale a la mesquita mayor e de la otra parte de la calle publica que va de la pescaderia de los moros a la gallineria"13, es decir, un horno de cristianos que había incorporado sin duda la famosísima fabricación

10 Villanueva ob.cit. y Torres Balbás, Leopoldo. "Plazas, zocos y tiendas de las ciudades hispanomusulmanas", $A l$ Andalus, XII, 1947, pp.437-476.

11 Bazán las cita como "casas con tiendas".

12 El baño, como es sabido, siguió siendo utilizado por los musulmanes en los primeros tiempos de la conquista hasta que su uso fue prohibido. En el caso de don Alvaro solo se cita como tal en los documentos de la compra.

13 Galera Mendoza, Ester, "Noticias sobre algunas de las primeras reformas urbanas de la ciudad de Granada tras la Conquista (1497-1513)", Cuadernos de Arte de la Universidad de Granada, 2000, p.15. 
dulcera granadina, una zona muy cercana a las casas de Bazán y un propietario igualmente ilustre: el corregidor ${ }^{14}$.

El último inmueble conocido como adquisición de don Alvaro en Granada es una huerta, comprada cuando la familia vivía ya en la ciudad, situada junto a su casa y que, por lo que sabemos, siguió siendo huerta hasta 1553.

Como es bien sabido, la Granada musulmana tenía numerosísimos huertos que poblaban su periferia pero que se entremezclaban también con el caserío de la ciudad dándole ese aspecto caracerístico y "fantástico", al decir del viajero Münzer. Las huertas de la ciudad, primorosamente cuidadas por sus habitantes musulmanes, perdieron gran parte de su valor y de su encanto conforme se perdía la población que las atendía, aunque los moriscos, cuya laboriosidad siempre fue alabada, mantuvieron aun durante mucho tiempo el testimonio de numerosos vergeles dentro de la urbe. La compra de una de estas huertas por don Alvaro de Bazán en 1497, nos servirá de ejemplo para conocer la trayectoria cristiana de estos inmuebles.

Así pues, todos estas propiedades adquiridas por don Alvaro el comendador, debieron mantenerse con pocas reformas durante los primeros años de residencia de la familia en Granada.

La casa en mejores condiciones serviría de residencia familiar y el resto sería sin duda alquilado a moriscos o cristianos para obtener una renta. Esta residencia familiar es citada siempre como las "Casas Principales", que, como es sabido, es la forma habitual de citar en el siglo XVI la sede primordial de un "linaje". En efecto, a partir del Bazán Comendador se inicia una nueva rama del linaje de los Bazán que llegará incluso a mayor relevancia que el mayorazgo primitivo.

La entidad representativa de estas casas y la sencillez de las ocupadas primeramente por la familia hace que poco después de la muerte de don Alvaro, su viuda comience el ordenamiento de estas propiedades pequeñas y variadas, realizando permutas con vecinos para reagruparlas. Así por ejemplo, en 1500, estando en Sevilla doña María, permuta una casa suya de la colación de Santa María la Mayor ${ }^{15}$, situada junto a su casa principal y que tiene "por delante la Calle Publica Real", por otras de Juan Alvarez Zapata que lindan igualmente con su casa principal y están situadas "en una calle que sale al pilarejo de la calle real", y que por ser de mayores dimensiones requieren el pago adicional de $32.500 \mathrm{mrs} .{ }^{16}$.

Este reordenamiento estaba relacionado sin duda con el cumplimiento de una claúsula del testamento de don Alvaro, referente a la fundación de un hospital en Granada, origen de lo que sería después el monasterio de Sancti Spiritus fundado en $1515^{17}$.

Hay pocas noticias posteriores sobre la casa y sobre la familia. En los años 20 sabemos que el primogénito (nacido entre 1491 y 1495) lucha en el bando real en las germanías de Valencia ${ }^{18}$ y comienza los asientos de galeras con el emperador ${ }^{19}$ siendo Capitán General de las Galeras de

\footnotetext{
14 No sabemos si la referencia alude al horno del conde de Tendilla que estaba muy próximo a la alhóndiga Zayda en 1505 (Villanueva Rico, ob.cit.1961, p.34). No lejos de esta zona estaba también el horno de don Alvaro que por aquellas fechas -1497- era regidor de Granada.

15 Toma el nombre, como es sabido, de la antigua iglesia cedida después a los franciscanos como convento.

16 A.M.S.C. $\operatorname{leg} 1 \mathrm{n}^{\circ} 3$

17 Véase nota 1

18 A.M.S.C. leg. $12 \mathrm{n}^{\circ} 11$, donde se especifica que "sirvió con 100 cauallos a su costa, peleando valerosissimamente con los alterados del Reyno de Valencia y en Xatiua rindió à los de la germania, obligandoles, à que tratassen medios de paz con el virrey don Diego de Mendoza". Pardo Molero documenta una orden de pago del virrey Diego Hurtado de Mendoza (primo de don Alvaro) correspondiente al sueldo de un mes a los jinetes de la compañía mandada por don Alvaro de Bazán, dada en Montesa en 1522 (Pardo Molero, Juan Francisco, La defensa del Imperio. Carlos V, Valencia y el Mediterráneo, Madrid, Sociedad Estatal para la conmemoración de los centenarios de Felipe II y Carlos V, 2001 p. 145 y nota 194)

${ }^{19}$ Las primeras noticias que tenemos de la familia Bazán relacionadas con el mar se refieren a Sancho de Bazán, un hermano del Comendador de Castroverde, quien, según Garibay, residió en Bilbao "haciendo una armada por mandado del Rey don Fernando el quinto contra el rey de Francia y no tuvo hijos" Garibay y Zamalloa, Estevan de. Tomo octavo de las obras no ympresas de..., Manuscrito 11115 de la Biblioteca Nacional de Madrid fol.340. Sobre las galeras de
} 
España en 1523. En 1525 contrae matrimonio con Ana de Guzmán y el 12-12-1526 nace su hijo Alvaro, futuro marqués de Santa Cruz, en Granada. Ese mismo mes Carlos V y su mujer abandonan la ciudad ${ }^{20}$ acompañados de la madre de Bazán nombrada guardadamas de la emperatriz, quien debió volver poco o nada a la ciudad, hasta la muerte de Isabel en $1539^{21}$.

Desde 1530 Bazán visita asiduamente Génova ${ }^{22}$, tiene relación con el embajador español en la República ${ }^{23}$ y con Andrea Doria, a quien acompaña en viajes por las costas españolas ${ }^{24}$ y aumenta su riqueza con la toma de One (Honein) ${ }^{25}$.

Mientras tanto, la familia Bazán se traslada a Málaga, a Granada y en 1535 a Gibraltar cuando don Alvaro es nombrado alcaide de su fortaleza. Este año es el de la empresa imperial más importante: la conquista de Túnez. Don Alvaro participa en el ataque a la Goleta y resulta honrado y enriquecido de nuevo ${ }^{26}$.

Bazán hay numerosa documentación en el archivo de la casa y naturalmente en el Archivo General de Simancas y especialmente en Guerra y Marina I.

20 Sobre su estancia puede verse: Vilar Sánchez, Juan Antonio, 1526. Boda y luna de miel del emperador Carlos V, Granada, Universidad de Granada y Real Mestranza de Caballería de Granada, 2000.

21 Sabemos que María Manuel está con la emperatriz en Valladolid en 1527 y en Toledo en 1529 y que tiene a su cargo a dos nietas, Isabel y María, a quienes favorece la emperatriz. Ambas nietas son hijas de Mencía, la hija menor de doña María, casada con Juan de la Cueva y seguramente muerta por entonces. Hay escrito de la emperatriz al "Mayordomo y Contador de la despensa y raciones de mi casa de recebir por dama a doña Isavel de bazan nieta de doña María Manuel Guardamayor de mis damas para que haya e tenga de mi de bestuario en cada un año 27.000 mrs. porque vos mando que los asentedes asi en los libros e nominas [...] hecha en Toledo 20-4-1529. La reyna y Juan Vazquez de Molina secretario de su magestad ..por su mandado". (A.M.S.C.leg. 10 n. ${ }^{\circ} 18$ ).

22 En 1532 sus galeras transportan desde Génova los encargos hechos por la emperatriz ( Archivo General de Simancas. Papeles de Estado. Génova, Legajo 1365 fol.1)

23 El embajador Gómez Suárez de Figueroa es importantísimo para la historia de las relaciones hispano-genovesas -incluidas las artísticas-. Probablemente relacionado con los Suaréz de Figueroa de la casa de Feria, desciende sin embargo de otra rama establecida en Italia. A pesar de la importancia histórica de su larguísima misión en Génova no hay ni una pequeña monografía sobre él y la mejor aportación es la efectuada recientemente por Rafael Vargas-Hidalgo, Guerra y Diplomacia en el Mediterráneo: correspondencia inédita de Felipe II con Andrea Doria y Juan Andrea Doria. Madrid, Ediciones Polifemo, 2002 pp. XIV-XVIII.

${ }^{24}$ Como se recordará, Andrea Doria es el más famoso condottiero marítimo de todos los tiempos; dando un espectacular giro a su política personal pasó al servicio de Carlos V en 1528 y será hasta su muerte el más fiel consejero, aliado y servidor de España. En 1529 las galeras de Andrea Doria llevan a Carlos V a Italia y el emperador reside en Génova 44 días; llega el 12-8-1529 y no puede ser hospedado en la villa de Andrea Doria en Fassolo porque está en obras. En 1531 Carlos V concede el Toisón de oro a Andrea Doria, le hace Príncipe de Melfi en Lucania y le da 25.000 escudos para las obras de su villa (Cadenas y Vicent, Vicente de, El protectorado de Carlos V en Génova. La "condotta" de Andrea Doria, Madrid, Instituto Salazar y Castro C.S.I.C., Hidalguía, 1977 p.156). En el archivo de Santa Cruz hay cartas de la reina informando a don Alvaro que Andrea Doria ha llegado a Barcelona con 30 galeras y que gente de la corte que ha venido en ellas dicen que son las mejores que nunca se vió "hagoslo saber porque se que holgareis"; poco después agradece a don Alvaro las atenciones que ha tenido con Andrea Doria y avisa a ambos de que han salido fustas de Argel (A.M.S.C.leg. 10. $\mathrm{n}^{\circ} 3$ y 5).

25 Allí gana once galeotas y hace cautivo al corsario Azán Arráez con muchas galeras y galeotas turquesas, lo que le vale la felicitación del emperador y la emperatriz. (A.M.S.C. leg.16, 17 y $10 \mathrm{n}^{\mathrm{o}} 24$ ).

26 En la campaña se hicieron según los contemporáneos 18.000 esclavos, muy valiosos para don Alvaro no solamente por su empleo en las galeras sino también por su venta libre. Sabemos que al marchar él de Tunez, dejó dinero a su capitán Julián para la compra de esclavos en La Goleta (A.M.S.C. leg. 15 s/n). Dada la importancia de la empresa y la repercusión publicitaria que tuvo en toda Europa omitimos referencias a las crónicas e impresos contemporáneos. Recordamos no obstante que la marcha de Bazán al final de la campaña de Túnez es recogida en la inscripción del tapiz Reembarque del ejército en La goleta, perteneciente a la rica serie de La conquista de Túnez, hecha por Guillermo de Pannemaker hacia 1554 y hoy en el Palacio Real de Madrid. La inscripción de la cartela superior del tapiz dice así: "Uelue el Emperador desde Rada a la Goleta y alli manda assentar el exercito en la parte donde antes staua [...]. Manda el Emperador fortificar la Goleta: y dexa en guarda della a don Bernaldino de Mendoça con Mill Spañoles. Embarcase el exercito casi mediado el mes de Agosto. Bueluese el infante don Luys con la armada de Portugal. El marques de Mondejar con las naues y gente que hauia traydo. Don Alvaro de Baçan con las galeras de España. Los Alemanes e Italianos en otras naues se boluieron a sus tierras $[\ldots]$ 
En 1536 pasa una larga etapa en Génova ${ }^{27}$, donde la obra nueva más importante de la ciudad es la villa de Andrea Doria en Fassolo, lugar de residencia de Carlos V en 1533.

El almirante había ido adquiriendo varias propiedades fuera de los muros de la ciudad, y allí, entre el mar y la montaña, edificó un magnifico palacio, rodeado de jardines y decorado espléndidamente. En sus obras intervino el pintor Perin del Vaga, salido de Roma tras el famoso saco y responsable también de los modelos y la supervisión de obras arquitectónicas y escultóricas. El introdujo las nuevas formas del arte romano, haciendo del palacio doriano el modelo de toda la renovación artística genovesa.

En 1531 llega a Génova Silvio Cosini, quien se ocupará de obras de escultura especialmente interesantes para nosotros ahora. El poder, la importancia y las relaciones de Andrea Doria hacían que su palacio fuera el más visitado de la ciudad y el elegido frecuentemente como modelo de los encargos hechos por flamencos y españoles, como vamos a ver seguidamente.

Aunque nada sabemos documentalmente sobre posibles obras en las casas de Bazán en Granada, podemos suponer que durante el primer período de viudez de María Manuel todos los recursos se emplearían en la construcción de la iglesia primero (1500-1504) y del monasterio de Sancti Spiritus después, por lo que sus Casas Principales, citadas en los documentos, siguieron siendo las compradas a los musulmanes, reformadas probablemente, pero no construidas de nuevo. Por ello la categoría modesta de la casa familiar granadina no debió considerarse muy de acuerdo con los nuevos cargos ni con las nuevas posibilidades económicas de don Alvaro.

El conocimiento personal de los nuevos palacios italianos (sin duda la Villa Doria) junto con la fiebre de construcciones al "antiguo" que se respiraba en Granada en la década de los treinta, debieron influir para que Bazán quisiera dar a sus casas un aspecto más acorde con su nueva categoría y con la nobleza que reclamaba para su linaje, por lo que hacia 1536 decide reformarlas. Si, como parece, la casa solariega era en esencia una casa musulmana no muy rica -según muestra la documentación- es probable que su dueño pensase hacer algo similar a lo hecho anteriormente en La Calahorra por los Mendoza, en el castillo de Vélez Blanco por los Fajardo y en su casa sevillana por los Henríquez de Ribera 28: renovar el patio y algunas partes de la casa con formas italianas y con elementos del material prestigiado y prestigioso, el mármol.

En cualquier caso, las noticias que poseemos nos indican que se pensó renovar o construir un patio (y probablemente una escalera) con piezas de mármol, hacer de la huerta un jardín moderno con dos fuentes monumentales, prestigiar sus habitaciones con ricas chimeneas y traer maestros italianos para dirigir la obra.

De todo ésto nada dicen las fuentes españolas ni el archivo familiar. Lo sabemos sólo por los documentos del Archivo de Estado de Génova publicados por Alizeri en 1870, revisados y comprobados por nosotros posteriormente y por algún escasísimo dato de archivos españoles.

\footnotetext{
${ }^{27}$ En abril de 1536 la reina le insta a que vaya urgentemente a Génova y en julio se realiza allí la visita de sus galeras, en relación con ellas su nombre aparece frecuentemente citado junto a los de Antonio y Andrea Doria (A.M.S.C. leg. $10 \mathrm{n}^{\circ} 5$ y 24.)

${ }^{28}$ Los modelos genoveses de nuevos palacios por estas fechas son muy reducidos, prácticamente la villa Doria de Fassolo. Los primeros palacios de nueva planta construidos con las nuevas formas son de la década de los 40 y pertenecen a Luca Grimaldi, Antonio Doria y Giovan Battista Grimaldi, todos ellos anteriores a la llegada de Alessi a la ciudad. Los propietarios citados están muy relacionados con España y especialmente Antonio Doria con los Bazán. No obstante también se hicieron reformas en viejos palacios como el de Martín Centurione, situado en la subida de San Francesco en Génova y reestructurado entre 1531 y 1534 con logias, escaleras y cornisas contratadas con Matteo de Carona. Sus fuentes se citarán como modelo en otros contratos. Este Martín Centurione fue embajador en España y su familia será muy importante para la construcción del futuro palacio de Bazán en El Viso pues actuará como su agente en Génova. Sobre los palacios genoveses véase Poleggi, Ennio, Strada Nuova, una lottizzazione del Cinquecento a Genova, Genova, Sagep, 1968.
} 
El primer documento corresponde al 19 de julio ${ }^{29}$ de 1536 y en él los maestros Gio.Giacomo della Porta milanés residente en Génova y Gio. Pietro de Pasallo, se comprometen con Martín de Pedriola, vecino de Guadix, en nombre de don Alvaro de Bazán, Capitán General de las Galeras de España, a fabricar 300 balaustres de mármol blanco, según las medidas expresadas en un dibujo adjunto al documento (perdido para nosotros); dichos balaustres habrían de ser como los de la capilla primera del lado derecho de la iglesia de San Teodoro de Fassolo, cuya factura valía, a juicio de los peritos, cinco sueldos de Génova cada uno; también habrían de hacer 24 piezas de cornisa de mármol (12 de diez pies cada una según medida indicada en el dibujo, y 12 de cinco pies) trabajadas según el dibujo; además 10 piezas de cornisa de mármol de 13 palmos cada una, medidas de España, según dibujo; 20 piezas de cornisa de mármol de seis palmos y medio cada una, medida de España y según dibujo ${ }^{30}$ y dos fuentes de mármol similares en forma y medida "a las que están en la casa del Príncipe Andrea Doria en Fassolo". Todo ello para entregar en su taller dentro del mes de septiembre del año presente y de acuerdo con el dibujo (desaparecido) entregado por dicho Martino a los maestros en presencia del notario, quien firmó el dibujo junto a Martino.

Martín de Pedriola, a su vez, promete a dichos maestros pagar los balaustres a razón de 29 sueldos de Genova cada uno y las cornisas a 20 sueldos de Genova por palmo, una con otra, y por ambas pilas 35 escudos de oro. Dicho Martín, en su nombre y en el dicho D. Alvaro, debe entregar esto a los maestros en Génova, o a un ciudadano genovés que se lo entregue a ellos. Por su parte, los maestros genoveses dicen que si no se les entrega el dinero como se ha dicho, debe entenderse que se prorroga el tiempo de trabajo y entrega de dichas obras, pues ellos no pueden trabajar sin dinero y si éste se retrasa, se retrasa el plazo de entrega por todo el mes de octubre próximo. En ese mismo día los maestros italianos prometen entregar a Martín de Pedriola una fuentecita con su pie y vástago y con una piña en la parte superior que dichos maestros tienen en su taller venida del jardín del difunto Martín Centurione ${ }^{31}$.

Dado nuestro desconocimiento de la casa granadina de los Bazán, los dibujos incluidos en el contrato podrían ayudarnos a conocer las obras realizadas para España, pero desafortunadamente se han perdido. En cuanto a las obras genovesas citadas en el contrato como referente, la suerte no es mucho mayor.

La iglesia de San Teodoro, cuya capilla es citada como modelo para los balaustres, estaba situada en Fassolo, no lejos del palacio de Andrea Doria, y era del patronato de los Lomellini, familia presente desde antiguo en Granada y con la que don Alvaro se relacionaba en Génova a causa de sus galeras. La iglesia fue demolida en 1870 y algunas de sus obras (relieves y pinturas) fueron transferidas a la nueva, inaugurada en 1876. Alizeri en su Guía de Génova de 184732 menciona esta primera capilla de la derecha, pero sólo para decir que tiene un cuadro de Magnasco, sin añadir nada más sobre la decoración. En su segunda Guía de $1875^{33}$ la iglesia ya ha sido derribada y, que sepamos no existen fotografías antiguas sobre la capilla ${ }^{34}$, por tanto nada se puede saber por ahí.

\footnotetext{
${ }^{29}$ Federigo Alizeri (Notizie dei Professori del disegno in Liguria dalle origini al secolo XVI. Genova, MDCCCLXX, V, pp.228-231) da abril en la transcripción, pero realmente es julio, el mismo mes en que se realiza la visita de las galeras de don Alvaro, como hemos visto más arriba. Quiero agradecer al Doctor Rattini su gentileza y ayuda en la transcripción. Documento $\mathrm{n}^{\circ} 1$ del apéndice documental transcrito nuevamente con las oportunas correcciones al texto publicado por Alizeri.

${ }^{30}$ Esto último lo omite Alizeri en la trascripción pero está en el documento.

${ }^{31}$ Documento $^{\circ} 1$ del apéndice documental, transcrito nuevamente con las oportunas correcciones al texto publicado por Alizeri. El Martín Centurione que aparece en el texto es el citado anteriormente en nota 31.

32 Alizeri, Federigo, Guida artistica per la città di Genova. Genova, presso Gio. Grondone, Q. Giuseppe Editore librario, MDCCCXLVI-MDCCCXLVII, II vol. p.1246.

33 Guida illustrativa del cittadino e del forastiero per la città di Genova e sue adiacente, Genova, Dai tipi dell'editore Luigi Sambolino, MDCCCLXXV

${ }^{34}$ Sobre la historia de la iglesia y sus obras transferidas puede verse Bosio Bernardino, Chiesa di S.Teodoro. Parrocchia ed Abbazia dei Canonici Regolari Lateranensi in Genova. Notizie storiche a cura di... Genova, 1965, que recoge bibliografía anterior.
} 
En cuanto a las dos fuentes (antes se había dicho siempre una) el modelo citado son las colocadas en el jardín del príncipe Doria. De las conocidas actualmente, solamente la colocada en el lado oeste del palacio corresponde estilísticamente a las fechas del contrato del Bazán. Esta fuente ha sido atribuida a Silvio Cosini, según dibujo de Perin del Vaga, y se cree realizada antes de 1533 en que marcha a Venecia, a pesar de otras suposiciones de Gorse ${ }^{35}$.

El número de balaustres (300) y los metros de cornisa encargados (103,16 m. aprox.) estudiados en comparación con los empleados en el patio de La Calahorra y en el de algún otro palacio genovés contemporáneo, nos hace suponer que iban destinados no solamente a la construcción de un patio interior, como era habitual en España, sino también a formar otra balaustrada, probablemente para una escalera.

Por estas mismas fechas se debieron encargar otras piezas cuyos contratos no se han encontrado por ahora. Como ejemplo podemos citar la chimenea y un escudo de los Bazán en mármol, a los que haremos referencia más adelante.

Como el trabajo era mucho y debía hacerse en poco tiempo, el 5 de agosto Gio. Giacomo della Porta toma como socios para las obras citadas más arriba a su hijo Guglielmo, ausente, y al maestro Nicolà de Corte, presente. Este último recibe ocho escudos de oro y un tercio por la tercera parte de los 25 escudos de oro que le corresponden ${ }^{36}$. Así pues ambos debían colaborar en este encargo y probablemente en otros, cuyos documentos no conocemos aún pero cuyos resultados están en España, como veremos más adelante.

Dos meses después, el 7-10-1536, los maestros Gio. Giacomo y Gio. Pietro certifican que han recibido de Baptista de Promontorio de Ferraris 275 libras y 13 sueldos de Génova por orden del dicho D.Alvaro, que son para liquidar las mencionadas obras de mármol.

Más tarde, el 25 de enero de 1537, Gio.Giacomo della Porta y Gio. Antonio de Pasallo, en nombre de su padre ausente, confiesan haber recibido del dicho Baptista de Promontorio de Ferraris, otras 151 libras y media como complemento de las 665 libras de Génova de todas las partidas citadas; al tiempo se comprometen a entregar la obra antes de la próxima Pascua de Resurrección, bajo pena de 25 escudos de oro si no lo hacen ${ }^{37}$.

El 29 de enero y el 14 de febrero de 1537 se firma un nuevo contrato con Nicolà de Corte escultor, mayor de 25 años, y Antonio de Semino pintor; ambos reciben de Baptista de Promontorio de Ferrariis, en nombre de D. Alvaro de Bazán ausente, cien escudos de oro imperiales y prometen embarcarse en la nave del patrón Juan Danda que está en el puerto de Génova y trasladarse al lugar de Granada, o adonde dijera y quisiera D. Alvaro, para trabajar en lo que se acordaren con él ${ }^{38}$.

Este nuevo contrato nos da nueva luz sobre la obra de las Casas Principales de don Alvaro. Para ellas se necesitaba no solo un maestro que montase las obras encargadas en Génova sino también un pintor, que ciertamente empezaría a trabajar a su llegada, por lo que ya tenían que estar dispuestos los espacios que había de decorar. Lógicamente la venida de un pintor a España estaba relacionada con una decoración al fresco, para lo que no había por entonces mano de obra española experta. Esta decoración supone también una nueva nota de "modernidad" en la casa de los Bazanes ya que, como se recordará, las primeras decoraciones de este estilo que se hicieron en

\footnotetext{
35 Gorse, George Lawrence : The villa Doria in Fassolo, Genoa, Brown University Ph.D. 1980. Por cierto que la especificación hecha en el contrato con Bazán sirve también para saber que en la decoración de los jardines de Fassolo existían ya antes de 1536 dos fuentes monumentales sin duda alguna similares o pareja para lugares equidistantes.

36 A.S.G. Not. Stefano Sauli Carrega. sc. 226 f. 9 doc. 430. Alizeri, Notizie, ob.cit. V, p.231. Documento n 2 del apéndice documental.

37 A.S.G. Not. Stefano Sauli Carrega. sc. 226 f. 9 doc. 430 (Documentos no publicados por Alizeri). Documento ${ }^{\circ}$ 3 del apéndice documental.

38 A.S.G., Not. Stefano Sauli Carrega. Fogliaz. 10, nº 2016 doc. 400 1537-1538. Alizeri, Notizie ob.cit. III, pp.360362. Doc. $\mathrm{n}^{\circ} 4$ del apéndice documental.
} 


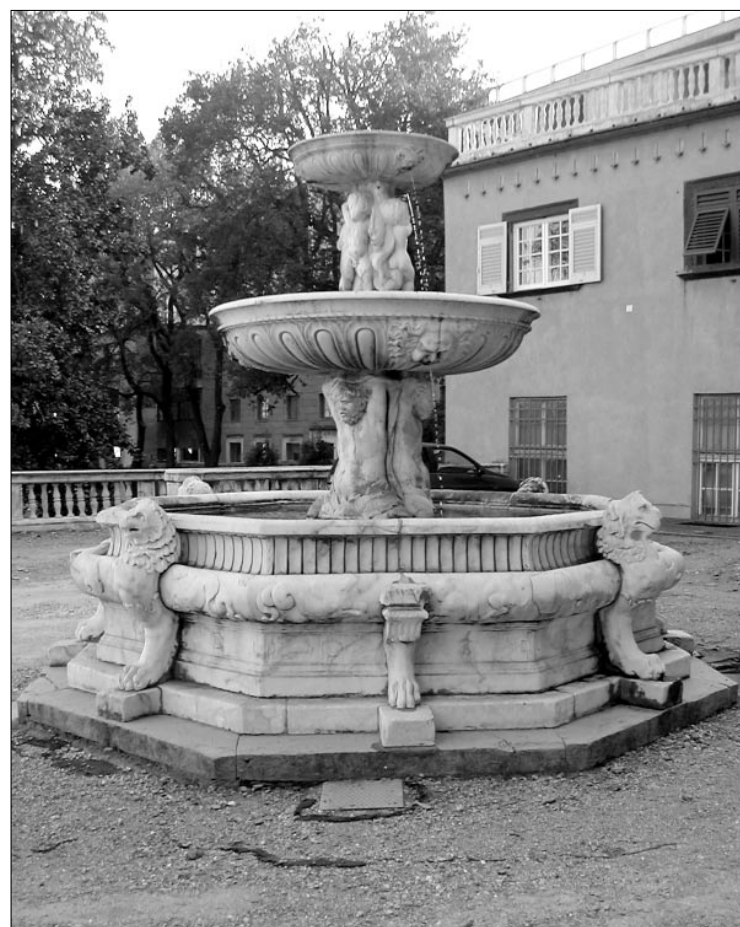

1. Silvio Cosini y taller. Fuente de la villa de Andrea Doria en Fassolo (Génova). Patio occidental. 1531-1533.

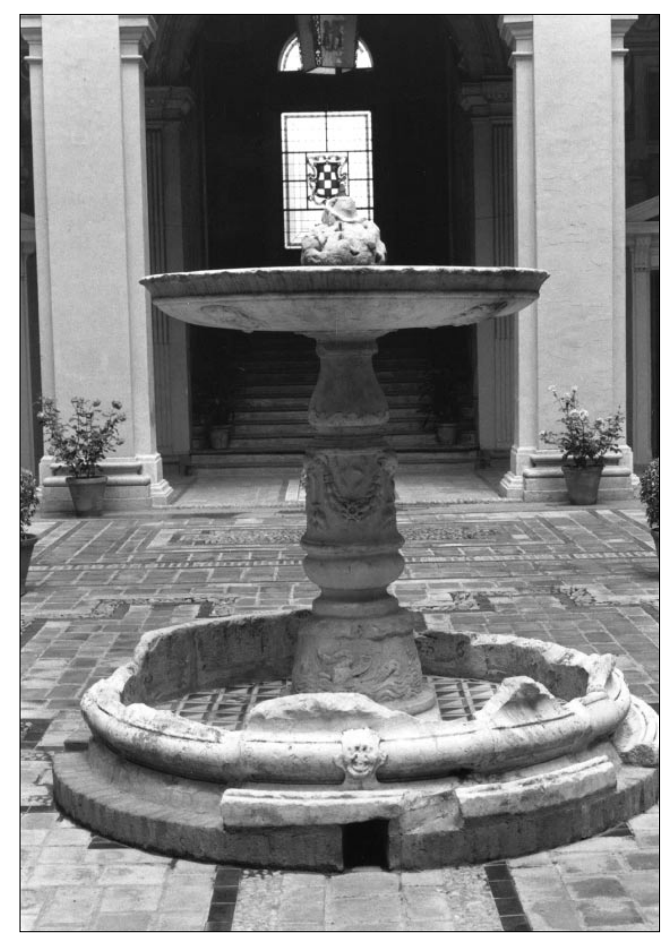

2. Gio. Giacomo della Porta y taller. Fuente del palacio del Viso (Archivo General de Marina). El Viso del Marqués (Ciudad Real). 1536-38

3. Gio. Giacomo della Porta y taller. Chimenea de Leda. Palacio de Carlos V. Granada. 1536-38.

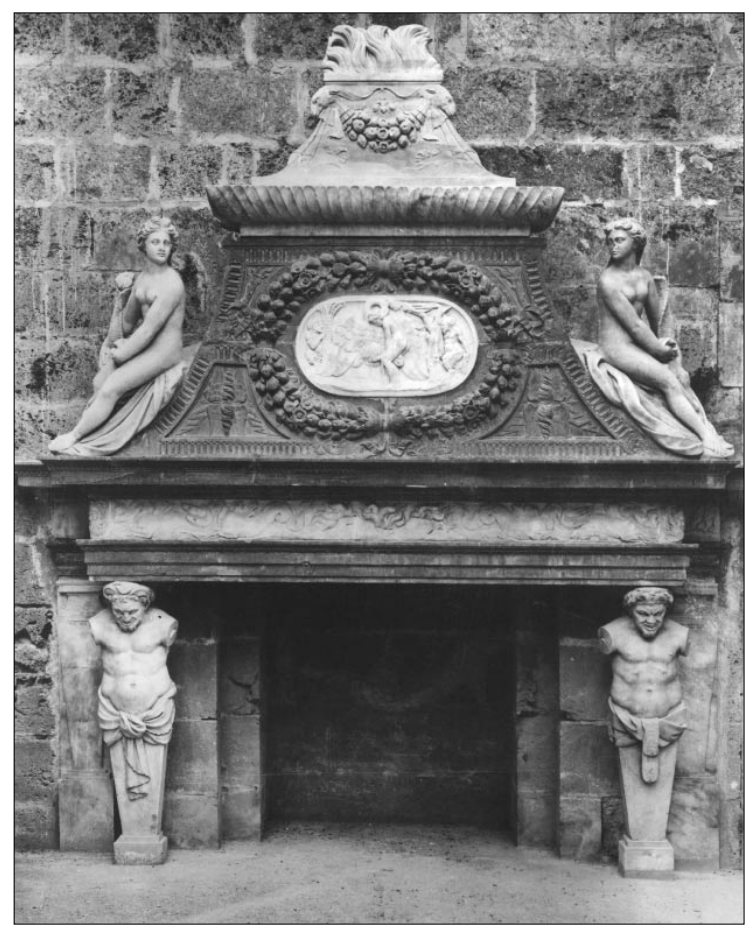


Granada fueron las de los pintores Julio y Alejandro en las habitaciones de Carlos V en La Alhambra cuyo primer documento conocido es de $1535^{39}$.

En estas circunstancias, hacia marzo o abril, debieron llegar a España los artistas genoveses, de los que no volvemos a tener noticias relacionadas con su trabajo para Bazán. Lo que sí sabemos es que en noviembre de 1537 Nicolà de Corte está trabajando en las obras reales de La Alhambra, donde permanecerá hasta su muerte muchos años después.

De Semino solo podemos suponer que vino a España y que su estancia fue prolongada, puesto que hasta 1543 no vuelve a ser mencionado en Génova. Lo más lógico es pensar que también Semino se incorporó a las obras reales de la Alhambra como pintor. Precisamente en 1537 se estaban terminando de pintar los llamados "Cuartos de las Frutas" y se iniciaba la pintura del corredor que va de la Sala de Comares a la torre de Abul Hayyay terminado en 1539. Después de esta fecha se continuó con la pintura de los espacios habilitados dentro de la torre musulmana que duraron siete años más. Semino podría ser el responsable de ciertas notas perinescas que hay en esta obra, pero las cuentas de La Alhambra conservadas no registran entre su pagos ninguno a Semino por lo que sigue en el misterio su trayectoria española.

Igualmente desconocido es el destino final de las obras enviadas a Granada.

Algunas fueron vendidas -como veremos más abajo- y otras fueron trasladadas a la nueva residencia familiar en la villa del Viso. Allí aparecen citados en el inventario realizado a la muerte de don Alvaro de Bazán en 1555: "seis pilas de mármol", "catorce barahustres de marmol blanco de genova" y "un escudo de marmol con las armas de bacan" 40 que sin duda corresponden a las obras encargadas para la casa de Granada.

Si recordamos que las dos fuentes encargadas en Génova habían de hacerse según el modelo de las existentes en la villa de Andrea Doria y observamos la fuente correspondiente a estos años que allí se conserva actualmente (fig. 1), comprobaremos que consta efectivamente de tres pilas por lo cual las seis inventariadas en El Viso podrían corresponder a este encargo.

Actualmente existe una fuente monumental colocada en el jardín del palacio del Viso (fig. 2) cuya tipología podría acercarse a la de la villa Doria. Aunque la española está bastante deteriorada es fácil ver que constaba de una pila inferior (de la que solo se conserva su moldura y parte del arranque de las paredes) un vástago central con otra pila o plato, decorado con acanaladuras y mascarones y es probable que tuviese una tercer plato perdido en la actualidad. Tanto la tipología de la fuente como los relieves de temas marinos ${ }^{41}$ en la parte inferior del vástago central o la decoración de guirnaldas en la parte central, podrían pertenecer a obras genovesas de esta tercera década del siglo XVI e indicar que la fuente formó parte del primer pedido hecho por Bazán, aunque las máscaras del plato superior tienen detalles decorativos posteriores que nos hacen dudar.

Ahora bien, ¿qué pudo suceder para interrumpir de forma tan rápida las obras de la casa de Granada y para suspender el contrato firmado con De la Corte y Semino en enero de 1537 ?

Carlos V, acuciado por la necesidad de recursos para sus campañas militares recurrió a la venta de bienes de las órdenes militares, y en junio de 1537 consiguió una bula de Clemente VII para poder desmembrar y vender algunos bienes de dichas órdenes a fin de conseguir dinero "para las invasiones de moros en España y Nápoles"42. Esta circunstancia ofreció a don Alvaro de Bazán la posibilidad de adquirir un gran señorío de enormes recursos económicos. Sin embargo tal posibilidad requería un desembolso enorme de capital y motivó que el interés principal de la familia se desviase de Granada y como primera medida se paralizaran las obras de las Casas Principales.

\footnotetext{
${ }^{39}$ López Torrijos, R.: "Los grutescos de Rafael y Udine en la pintura española. La estufa y la logia de Carlos V", Storia dell'Arte, nº0, 1987, p. 171-184.

40 A.M.S.C. leg $43 \mathrm{n}^{\circ} 40$.

${ }^{41}$ Recuérdene los relieves con Neptuno y Anfitrite y Neptuno calmando la tempestad hechos por Nicolà da Corte en la fachada meridional del palacio de Carlos V.

42 A.M.S.C. leg. $5 \mathrm{n}^{\circ} 8$.
} 
Durante 1538 -en noviembre de cuyo año nace en Granada Alonso, el penúltimo de los hijos de Bazán- se van a realizar las operaciones necesarias para la adquisición del nuevo señorío.

En abril de ese año, D.Juan Pimentel, Comendador del Viso y Santa Cruz da el consentimiento en Barcelona para que ambos lugares sean desmenbrados de la orden de Calatrava y vendidos por el emperador, y ordena la tasación de estos bienes ${ }^{43}$ y en mayo, desde Valladolid, don Juan Zapata de Burgos, Procurador General de la orden de Calatrava, da poder para hacer la tasación. En octubre, el emperador faculta a don Alvaro de Bazán para vender los bienes de su mayorazgo necesarios para pagar la compra del Viso y Santa Cruz "cuya venta está concertada" y en diciembre del mismo año le permite que pueda tomar sobre sus bienes censos perpetuos ${ }^{44}$. En diciembre, desde Toledo, el emperador da provisión para desmembrar las villas del Viso y Santa Cruz de la Orden de Calatrava y para que Ruy Díaz de Velasco tome posesión de las dichas villas "que tenía la mesa maestral de Calatrava y que ha vendido a Don Alvaro de Bazán"45.

La escritura tiene lugar en Toledo el 22 de marzo de 1539 y el precio es de 26 quentos 208.626 mrs. (es decir, 69.916 ducados aproximadamente) ${ }^{46}$, más $414.636 \mathrm{mr}$. que ha de entregar a la orden de Calatrava de juro de heredad en recompensa de las rentas perdidas. Para pagarlo, don Alvaro comienza vendiendo la villa de Vélez de Banaudalla y algunas posesiones de la ciudad de Granada; empeña las rentas de las sedas de Granada y establece una serie de censos sobre sus bienes, pidiendo dinero contante a banqueros genoveses. Más tarde vende los lugares de Fonelas y Gorafe. Durante años, las deudas sin pagar y los intereses acumulados de los préstamos le harán ir estableciendo nuevos censos y vendiendo bienes del mayorazgo de Granada.

Mientras tanto, en 1539 también, muere la emperatriz y doña María Manuel vuelve a Granada con las nietas que tenía a su cargo. Mientras su hijo se ocupa del nuevo señorío adquirido y su familia se prepara para el traslado de residencia, ella se hace cargo de la casa granadina, cuya historia ira pareja a su vida, ya que su marido había establecido en el testamento que la hacienda se entregase al heredero cuando tuviese veinticinco años pero que las casas, muebles y heredades de Granada quedasen para doña María mientras viviese ${ }^{47}$.

Finalmente la familia de don Alvaro se traslada al Viso y allí nace, en abril de 1540, su hijo Juan.

Doña María queda en la casa de Granada y abre una comunicación directa con la iglesia del monasterio de Sancti Spiritus colindante y fundado por ella, estableciendo allí una tribuna para oir misa. Mientras vivió María Manuel la casa permaneció inalterada. Ella, que poseía bienes propios considerables, había criado a algunas de sus nietas y una de ellas, llamada igualmente María Manuel, fue la encargada de mantener parte de las casas principales dentro de la familia Bazán.

La familia trasladada al Viso sigue pendiente de las deudas por los préstamos recibidos de banqueros genoveses y los intereses de los censos establecidos para pagar la compra de su señorío. Don Alvaro vuelve a vender propiedades y recibe nueva autorización del emperador para enajenar bienes del primer mayorazgo. Vende Fiñana y Casabermeja al Hospital de San Juan Bautista "que fundó y dotó en la ciudad de Toledo el Cardenal don Ivan Tauera"48, reservándose solo unas casas, un baño, un horno y un mesón en la fortaleza de Fiñana.

La situación económica es delicada y prueba de ello es que doña María vende parte de los materiales importados de Génova por su hijo, por ejemplo una chimenea, cuya entrada se registra en las cuentas de la Alhambra el 29 de diciembre de 1546: "una chimenea que se compró de Doña

\footnotetext{
43 A.M.S.C. Leg $5 \mathrm{n}^{\circ} 10$.

44 A.M.S.C. leg. $2 \mathrm{n}^{\circ} 12$.

45 A.M.S.C. $\operatorname{leg} 5 \mathrm{n}^{\circ} 11$ y 12.

46 A.M.S.C.leg. 2.n.12.

47 A.M.S.C. leg. $43 \mathrm{n}^{\circ} 1$.

48 A.M.S.C. Leg. 2. n.12. El precio fue 10.979.214 mrs.
} 
María Manuel, de mármol y piedra negra de figuras, y talla de follajes de Genova, que costó $200.000 \mathrm{mrs} " 49$.

Esta chimenea que se ha conservado ${ }^{50}$-actualmente está en el palacio de Carlos V, en una de las salas del Museo de Bellas Artes- nos permite comprobar el tipo de obras que se encargaron para la casa (fig. 3). Aunque no conozcamos el contrato original, dadas las circunstancias vistas anteriormente, se debió encargar antes de 1539 y como en el caso de las fuentes, el modelo debió ser el existente en la villa Doria de Fassolo, cuyas chimeneas hizo Silvio Cosini en 1533 e imitaron Giovanni Maria Passallo y Antonio di Nove de Lancio ese mismo año a petición de Jean de Boussu escudero de Carlos V51.

La chimenea es de mármol y piedra negra de Promontorio, los materiales más utilizados en Génova, cuyo contraste permitía enriquecer el lenguaje de las piezas. El modelo consiste básicamente en dos atlantes de mármol que sostienen un entablamento sobre el que descansa la campana, la cual tiene en la parte central un medallón de mármol con figuraciones historiadas, un coronamiento con motivos clásicos y dos figuras femeninas en los laterales, igualmente de mármol blanco.

En el caso de Bazán el conjunto está sostenido por dos hermes, el medallón de la campana representa la unión de Júpiter y Leda y las figuras laterales son dos ninfas desnudas. El relieve de Leda y el cisne es copia de una obra helenística de gran éxito en el Renacimiento, difundida por el grabado y solicitada por los coleccionistas de antigüedades, como el primer Duque de Alcalá que compró en Italia un relieve con esta misma imagen -aunque incompleta en sus laterales- que hoy puede verse en su palacio sevillano ${ }^{52}$, pero que llegó a España después de que la chimenea genovesa estuviese en la Alhambra ${ }^{53}$.

49 Oliver Hurtado, José y Manuel, Granada y sus monumentos árabes, Málaga, 1875 p.499. Manuel Gómez Moreno daba noticia de esta compra en 1874, refiriéndose a un documento recogido por él en el archivo de la Alhambra y fechado el 29-12-1548: "Se pagó a Daaría Manuel cierta cantidad de maravedises á cuenta de los cien mil en que se le compró una chimenea de mármol y piedra negra, de figuras y talla de follaje de Génova" ("Chimenea del Renacimiento en la Casa Real árabe de la Alhambra" El Liceo de Granada, 1874, p.264). Aunque en realidad la compra se efectuó en 1546 como puntalizó después en su Guía de Granada, Granada, Imprenta de Indalecio Ventura 1892 p.106 [edición facsímil de 1998]). El documento del Archivo de la Alhambra no ha podido ser encontrado después por lo que no ha podido comprobarse la exactitud de fechas y precio.

50 Anteriormente la chimenea se desmembró, parte de sus elementos sirvieron para formar un altar instalado en la sala del Mexuar y otros -como los dos personajes femeninos de la parte superior-fueron almacenados en un espacio de la Alhambra, que por ello recibió el nombre de "Sala de las Ninfas", según podemos comprobar por fotografías y publicaciones antiguas. Véase bibliografía citada en nota anterior, también "Júpiter y Leda" Semanario Pintoresco Español, 1850, p.92; López Torrijos, Rosa, "La relación del primer marqués de Santa Cruz con las artes. Datos inéditos sobre obras y colecciones", en El arte en las cortes de Carlos V y Felipe II, Madrid, Centro de Estudios Históricos, C.S.I.C., 1999 pp.409-418 y más recientemente Estella Marco, Margarita, "La importación de esculturas italianas. Obras en España del taller de los Della Porta, de Gianbologna y del Nacherino" (en prensa, pero cuya lectura nos ha facilitado muy amablemente).

51 Parma Armani, Elena: "Una suolta internazionale" en La scultura a Genova e in Liguria. Dalle origini al Cinquecento. I Genova, editoriale Fratelli Pagano, 1987, p. 280. Jean de Hennin-Liétard, señor de Boussu, encarga en Génova numerosas obras para el palacio de su señorío. Los contratos se firman además de con Passallo y Nove di Lancio con Gio. Giacomo della Porta y Nicoló da Corte según dio a conocer Alizeri. Los escultores por tanto son los mismos que trabajaron para Bazán. Sobre el palacio de Boussu puede verse: De Jonge, Krista, Las empresas arquitectónicas del emperador y de su Corte en los Paíes Bajos. El contexto europeo, en Carolus. Madrid, Sociedad Estatal para la Conmemoración de los Centenarios e Felipe II y Carlos V, 2000 pp. 35-53.

52 Lleó Cañal, Vicente: La Casa de Pilatos, Madrid, Electa, 1998, p. 54.

53 Sobre la iconografía del relieve de Leda y sus modelos antiguos véase: Alcalde Martin, Carlos y Torné Poyatos, $\mathrm{M}^{\mathrm{a}}$ Irene. "La chimenea genovesa del Palacio de Carlos V y el mito de Leda" Florentia Iliberritana. Revista de Estudios de Antigüedad clásica. Homenaje al Profesor Dr. Manuel Sotomayor Muro en su 75 aniversaio, 1997, $\mathrm{n}^{\circ} 8$ pp.19-38

54 Parma, ob.cit. p.282-285 
4. Anton van den Wyngaerde. Vista de Granada (Viena 36). National Bibliothek de Viena. 1567.

5. Planta de la casa de María Manuel en Granada. (Archivo de los Marqueses de Santa Cruz). $1553-1560$
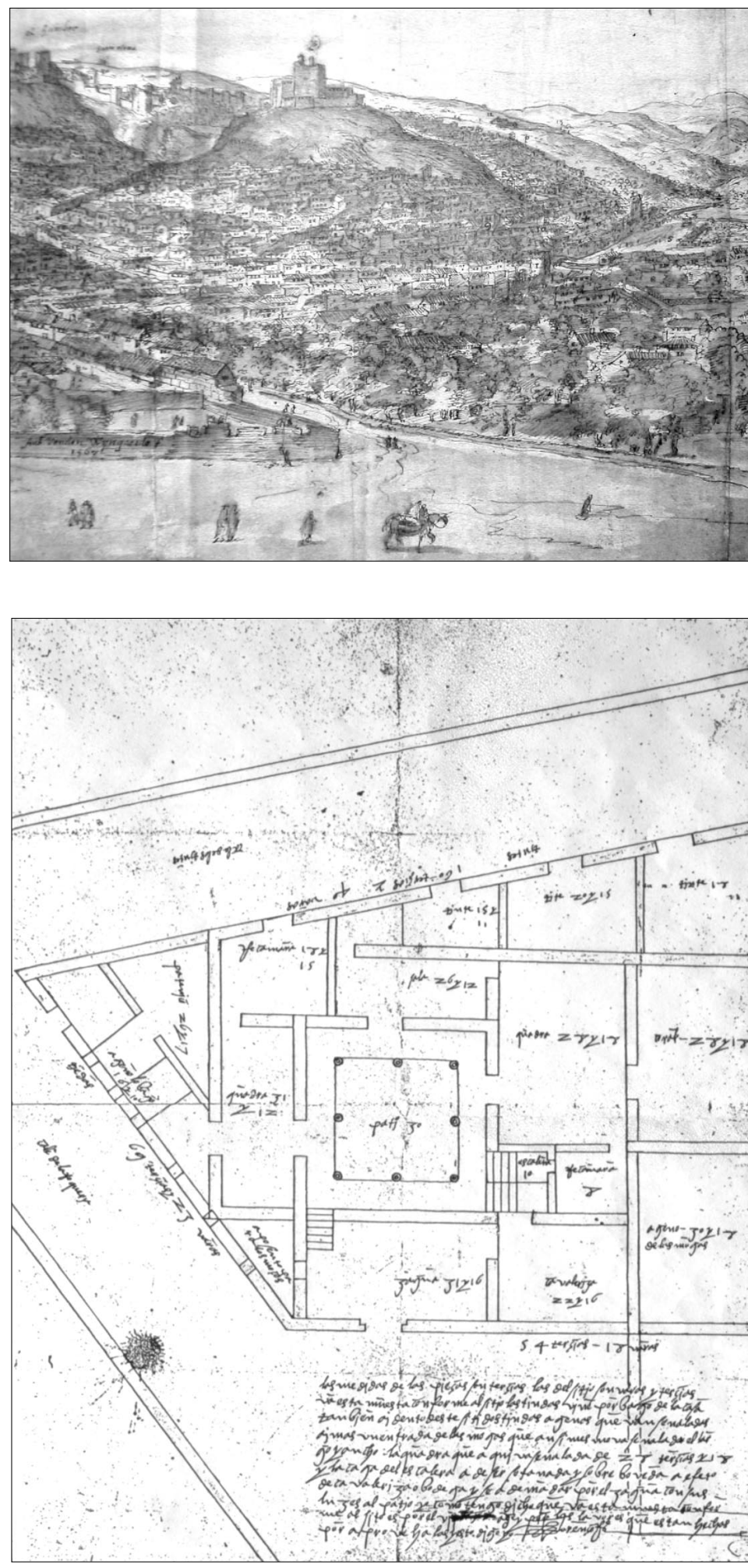

AEA, LXXIX, 313, ENERO-MARZO, 23-42, 2006, ISSN: 0004-0428 
Del modelo realizado para Bazán por el taller de Della Porta podemos ver aun en Génova algunos ejemplares muy similares pero posteriores, como los del palacio Grimaldi alla Meridiana y el palacio Balbi-Senarega (proveniente del palacio Nicola Cicala) ${ }^{54}$.

Así pues, las casas de los Bazán en Granada no llegaron a utilizar tan preciados materiales y cuando se procedió a su venta, seguían siendo básicamente el conjunto primitivo del viejo comendador de Castroverde, situado junto al monasterio fundado por su familia.

Sobre su forma o aspecto nada nos aporta ni la documentación conocida ni la vista de Granada de Antonio van den Wyngaerde (fig. 4) ni la plataforma de Vico, que solo sirven para ubicar la casa que ya sabemos situada junto al convento de Sancti Spiritus, éste sí señalado en ambas vistas.

María Manuel había previsto en su testamento de 1547 que una vez desaparecida ella, su hijo vendería las casas de Granada ${ }^{55}$ y efectivamente así sucedió.

Las primeras noticias son de 1553 cuando su nieto, también llamado Alvaro de Bazán, está en Granada con un poder de su padre para disponer de las Casas Principales "con su huerta y corral y patio y plaza delante con todo lo demás anexo"; él vende en su nombre y en el de su padre las casas del mayorazgo de Granada al convento de Sancti Spiritus por 5.737.500 de maravedís ${ }^{56}$. El convento se queda con una parte de la casa "donde está la Portada y las armas de Bazan" 57 y de la huerta, y para ayudarse en el pago a don Alvaro vende otra parte de las casas a don Gabriel de Cordoba por 2.092.500 maravedíes. Aquí es donde se edificaría después el palacio de los Fernández de Córdoba ${ }^{58}$. Los entresuelos y la huerta situados junto al monasterio, en la plaza que sube desde el puente de la Gallinería hacia la Plaza Nueva se ponen en almoneda, divididos y deslindados.

Doña María Manuel, sobrina de don Alvaro el Viejo, soltera y criada con su abuela del mismo nombre ${ }^{59}$, es la compradora de todos los entresuelos de las casas principales que caen sobre la huerta, de un solar de los hechos en terrenos de la huerta y de un pedazo de la huerta. Paga por ello 1.140 .000 maravedíes ${ }^{60}$. Como se han hecho nuevos solares y tiendas, los entresuelos llegan hasta el lugar adonde "se ha de abrir la calle que se ha de hazer para dar entrada [a los nuevos locales]". Dicha calle ha de salir a la de los Roqueros que baja de la Plaza Nueva al monasterio de Santi Spiritus y será la futura calle de los Tintes.

Otro trozo de huerta se vende al monasterio y otros solares y tiendas se venden a particulares.

55 A.M.S.C. leg. $43 \mathrm{n}^{\circ}$ 4. En el testamento indica: "si se vendiere esta casa mando que la tribuna que en ella esta que sale a la yglesia de las monjas deste mi monesterio en que yo oya missa o qualquiera otra bentana que a la dicha yglesia sale mando que luego que se vendieren las casas se cierre".

56 A.M.S.C. leg. $2 \mathrm{n}^{\circ} 12$.

57 Así lo hace constar Francisco de Paula Valladar en "D. Alvaro de Bazán en Granada. II. La casa de los Bazanes en Granada", Revista Contemporánea, 1888, t. 69 p. 240.

58 Véase Barrios Rozua ob.cit. pp.292-294. Como se deduce de la documentación anterior, la parte de los Bazán no fue derribada en 1530 como se indica, sino mucho más tarde, lo que explica también que la portada de los Fernández de Córdoba no fuese labrada hasta 1592. En 1688 Cecilio Bernal, en nombre del convento, manifiesta que las escrituras originales de fundación y donación del convento no se encuentran en él, que tampoco las tiene el marqués de Santa Cruz y que se ha perdido el protocolo del archivo correspondiente a ese escribano y a esa fecha. Dado que se han buscado las escrituras por todas partes sin éxito, ahora solicita al notario las pida a don Juan Fernández de Córdoba, vecino de Granada y descendiente de los que compraron al convento las casas de los Bazán en las que él vive ahora, para sacar copia de ellas. Poco después Fernández de Córdoba exhibe en efecto, las escrituras ante el notario "porque son de su mayorazgo las casas" (A.M.S.C. leg. $51 \mathrm{n}^{\circ} 1$ ).

59 Esta coincidencia ha creado la confusión existente, aunque por aquellos años la abuela ya estaba muerta.

60 A.M.S.C. leg. $1 \mathrm{n}^{\circ} 4$ y 5. Compra además "la mitad de toda el agua que pertenece a la casa y huerta, del agua limpia e sucia, excepto medio real de agua para el monasterio" y según se indica, doña María obtiene estos bienes por tanteo, por ser sobrina del propietario que ya tenía capitulada su venta a Gonzalo Gutiérrez para pagarle el censo establecido sobre dichas casas. El dinero de María Manuel va a parar a dicho Gonzalo.

61 Valladar dice que en la huerta y en otro pedazo de casa se labraron estos dos últimos palacios (Valladar ob.cit.II

AEA, LXXIX, 313, ENERO-MARZO, 23-42, 2006, ISSN: 0004-0428 
Así pues, las Casas Principales de los Bazán en Granada fueron vendidas en diversas partes y algunas de ellas destruidas. En su lugar se construyó la casa de los Fernández de Córdoba, las del conde de Alcudia y el marqués de Algarinejo (según Valladar ${ }^{61}$ ) y una nueva de María Manuel.

Esta última es la que revertería más tarde a don Alvaro de Bazán y de ella podemos saber algo más pues contamos con una planta del siglo XVI conservada en el archivo de los Santa Cruz (fig. 5). La planta corresponde a una construcción situada entre la calle de los Tintes (ya abierta), la calle de la Roquería, la placeta de Sancti Spiritus y terrenos del monasterio. Es una planta irregular en cuyo interior se encuentra una vivienda de espacios mayoritariamente ortogonales, rodeado de pequeños locales independientes, de plantas muy desiguales.

En la planta general se indican las medidas perimetrales de todo lo construido y las parciales de cada una de las piezas. Además se señala la función de los espacios y se añade una nota del autor de la planta. Tanto el papel como la grafía corresponden al siglo XVI aunque en el archivo estaban incluidos en un expediente del siglo XIX $^{62}$.

La vivienda está organizada en torno a un pequeño patio porticado de dos arcos por lado. La entrada se realiza por la fachada de poniente abierta a una "placeta". Existe además una entrada secundaria por la calle de los Tintes. La casa dispone de un amplio zaguán situado a un nivel inferior respecto al patio y se comunica con él por una escalera lateral que impide ver el interior desde la entrada. El zaguán da paso a una caballeriza y a un aposento triangular "para los mozos". El ingreso desde el zaguán se realiza por el lado occidental del patio que no dispone de ningún otro hueco en toda esta fachada. El patio está comunicado en su lado norte con una quadra rectangular que se comunica en eje longitudinal con una recámara que da salida a la calle de los Tintes y está abierto en su lateral izquierdo a un pequeño espacio muy irregular cuya función no se indica. En el lado oriental del patio se sitúa el ingreso a una sala -de dimensiones más reducidas que la quadra anterior- en cuyo fondo se abre paso a otro pequeño espacio lateral sin denominación. Finalmente en el lado sur se sitúa el ingreso a otra quadra grande y en el ángulo suroeste se encuentra la escalera de subida a la planta superior. La caja de la escalera tiene detrás una pequeña recámara comunicada con la quadra de este mismo lado.

Alrededor de estos espacios se encuentra, en el lado que linda con el monasterio, un corral y un espacio rectangular perteneciente a las monjas. En los otros dos lados hay espacios independientes que corresponden a tintes, tiendas y un pequeño patio triangular.

Al pie de la planta una nota del autor indica: "Las medidas de las pieças son terçias las del sitio son varas y terçias va esta muestra conforme al sitio las tiendas vienen por bajo de la casa tanbjen aj dentro deste sitio dos tiendas agenas que van señaladas aj mas un entrada de las monjas que ansimesmo va señalada el largo y ancho: la quadra que aqui va señalada de 28 terçias y 18 [la mayor] y la caja del escalera a de ser sotanada y sobre boveda a efecto de cavalleriza o bodega y se a de mandar por el zaguan con sus luzes al patio y como tengo dicho que va esta muestra conforme al sitio es por el (tachado) y por las lavores que estan hechas por aprovecharlas y esto digo yo. Firmado: Lorenzo $\mathrm{R}(\text { ? })^{63}$.

De esta manera podemos saber que la planta corresponde a lo que su autor se propone hacer en los terrenos adquiridos por doña María Manuel (solar, huerta y entresuelos), aprovechando lo ya existente. Se marcan en planta los espacios ajenos porque en el piso superior la casa de doña María se ampliaba al contar con los entresuelos situados sobre otras propiedades. Igualmente se marcan los solares y tiendas que se hicieron alrededor y que en parte se vendieron.

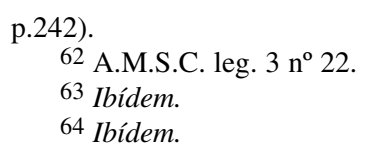


Por descripciones posteriores podemos comprobar que la planta corresponde a lo que se construyó realmente para doña María, que el piso principal era bastante mayor por contar con habitaciones situadas sobre propiedades ajenas y que el piso tercero y último era una torre pequeña de cañizo. Además la casa tenía "una tinaja pequeña un pilar y fuente todo de aguas corrientes"64.

Ahora, si examinamos con detenimiento la planta y las descripciones posteriores, podremos comprobar como la casa construida después de 1553 constituye en sí misma un buen ejemplo de la simbiosis castellano-morisca presente en la construcción granadina del siglo XVI.

En la planta baja se sitúa el patio central (característica árabe y cristiana) pero se construye con galerías en los cuatro lados (nota distintiva castellana), la entrada desde la calle se hace por un amplio zaguán (característico de los conquistadores) pero se comunica con el patio por un hueco lateral que impide ver el interior desde la entrada de la calle (característica árabe). La habitación principal es una sala alargada opuesta a la entrada y que su utiliza como vivienda de verano (casa árabe). El piso superior aumenta su superficie extendiéndose sobre el piso bajo de casas contiguas (muy común en la Granada musulmana). La casa tiene tres pisos (lo que no es habitual hasta después de la conquista) pero cuenta con una pequeña torre mirador (característica árabe). También tiene corral (común en los cristianos) y doble puerta de ingreso (árabe). Finalmente las tiendas son pequeñas, agrupadas, de una sola habitación y ocupan espacios irregulares rodeando la casa (árabe).

Como se percibe, hay una pervivencia de características musulmanas y una incorporación de elementos cristianos que se convertirán en constantes de la arquitectura granadina ${ }^{65}$.

Como hemos dicho anteriormente doña María carecía de descendientes directos y todos sus bienes fueron destinados a una sobrina de su mismo nombre -María Manuel- hija de su hermana la condesa de Santisteban y que sería segunda esposa de don Alvaro de Bazán, por entonces ya marqués de Santa Cruz. La tía contribuyó generosamente al matrimonio aportando buena parte de la dote, además de regalar a su sobrina un ajuar riquísimo ${ }^{66}$. Al final de sus días la propietaria de la casa manifestó el cariño que tenía tanto a María Manuel como a Alvaro de Bazán, dejando heredera de todos sus bienes a su sobrina y, en caso de no tener sucesión, a su marido don Alvaro.Así fue como parte de las Casas Principales de los Bazanes de Granada volvieron a poder de la familia pocos años después de ser vendidas.

En 1581 la ya marquesa de Santa Cruz, María Manuel, declara tener como hacienda propia en Granada "unas casas de morada junto al monasterio de Santi Spiritus y nueue tiendas de tintes en la calle de la roqueria" 67 . En 1584, los marqueses instituyeron con éstos y otros bienes un nuevo mayorazgo en Granada para Francisco, su segundo hijo que murió muy joven, la herencia pasó al tercero que no tuvo sucesión y en 1609 pasó a su sobrino Alvaro, II marqués de Santa Cruz ${ }^{68}$. A partir de entonces la casa y el patronato del monasterio de Sancti Spiritus permanecieron siempre en poder de los marqueses de Santa Cruz.

En el siglo XVIII se arrienda la casa como lo estaban ya los tintes y demás espacios y se da buena cuenta del mal estado del inmueble 69.

En el XIX se acrecienta la ruina y en 1849 el arquitecto Fabio Gago hace un reconocimiento minucioso de la casa y manifiesta el gran peligro de ruina que la amenaza, acrecentado por la

\footnotetext{
65 Sobre casas del siglo XVI existentes todavía en Granada puede verse Castillo Noguera, Ma Pilar: "Relación de edificios domésticos granadinos de los siglos XVI, XVII y XVIII", Cuadernos de Arte de la Universidad de Granada, 1974, pp. 359-398. En este trabajo se puede comprobar la presencia de numerosos elementos conservados en estas casas-palacio comunes a los citados en la casa Bazán.

66 Sobre ésto puede verse: López Torrijos, Rosa: El Marqués de Santa Cruz y Felipe II: aspectos de su vida familiar en Nápoles en Felipe II y las Artes, Actas del Congreso Internacional, Madrid, 2000, págs. 117-124.

67 A.M.S.C. leg. $8 \mathrm{n}^{\circ} 5$.

68 A.M.S.C., leg. $3,^{\circ} 17$.

69 A.M.S.C. leg. $53 \mathrm{n}^{\circ} 6$.

70 A.M.S.C. leg $3, n^{\circ} 22$ y leg. $2 n^{\circ} 58$.
} 
destrucción del monasterio colindante de Sancti Spiritus. En 1855 se hace una valoración de la misma, en la que teniendo en cuenta su estado ruinoso y que se ha edificado delante de ella "por efecto de la alineación que se propuso hacer y ha llevado a cabo el Excmo. Ayuntamiento de esta ciudad" quedando por tanto sin vistas ni ventilación, se aprecia en 16.000 reales. En 1856 se procede a su venta ${ }^{70}$ y a finales del siglo XIX se derriba.

Termina así la vida de las Casas Principales de los Bazán en Granada ${ }^{71}$, cuya historia documental conocida comienza en 1418 con las primeras ventas entre musulmanes.

Esta dilatada y documentada historia nos permite comprobar el modo de implantación de los primeros hidalgos cristianos en la Granada recién conquistada. Con el ejemplo concreto de la familia Bazán podemos conocer la forma y el interés de sus primeras adquisiciones en la ciudad y el desarrollo de su habitat, adaptando primero la casa musulmana, "rehabilitándola" hacia las nuevas formas importadas de Italia cuando se le quiere dar prestigio nobiliario, o utilizando una combinación más sencilla de formas árabes y cristianas, en una fórmula que constituye lo más peculiar y habitual de la casa granadina hidalga.

Apéndice documental. (Se han rectificado los errores y omisiones de los documentos publicados por Federigo Alizeri en Notizie dei Professori del disegno in Liguria dalle origini al secolo XVI. Genova, MDCCCLXX- vol. III, pp.360-362, vol..V pp.228- 231)

Doc. $\mathbf{n}^{\circ}$ 1. +In nomine Domini Amen: Magistri Iohannes Iacobus de la Porta de Mediolano habitator in Ianua q. Bartholomei et Iohannes Petrus de Pasallo piccapetrum q. mag. antonii [...] promittunt D. Martino de Pedriola Vicino de Guadis presenti et acceptanti nomine et vice Ill.D.D.Alvari de Basan Cappitanei Generalis triremium Hispanie absenti et me Notario quatenus expediat pro eo stipulanti etc. sibi Martino dicto nomine facere et fabricare bene et diligenter et ex bono marmaro albo balaustros tricentos mensure dessigni di quo infra dicetur in lungitudine et laboratos in omnibus iuxta formam illorum positorum in Capella prima a lattere destrro (sic) ingrediendo in Ecclesia Sancti Theodori de Fassolo et quod judicio peritorum erunt et magis valebunt de factura soldos quinque Ianue pro singulo eorum quam balaustros illos dicte Capelle: ac etiam petios viginti quatuor cornicis marmori in quibus esse debent cornises (sic) duodecim de pedibus decem singula mensure in designo contente et alii pecii duodecim vadunt in peciis viginti quatuor mensure de pedibus quinque pro singula cornise super dicto numero petiorum viginti quatuor laboratas conforme dessigno: Item petios decem de cornise integros marmari de parmis tresdecim ad mensuram Hispanie singulo parmo etiam conformi dicto dessigno: Item petios viginti de cornice marmari di parmis cum dimidio ad mensuram hispanie pro singulo etiam conforme dicto dessigno. Item pillas duas marmari pro brachile laboratas et in magnitudine ac in laboreriis prout sunt ille due pille Ill. D. Principis Andree de Auria existentes in palacio Fassioli prefati Ill.D. Principis et que omnia marmora et laboreria predicta dicti mag. Iohannes Iacobus et Iohannes Petrus in solidum ut supra perfecta et fabricata dare traddere et consignare promisserunt et promittunt prefato Ill. D. Alvaro absenti ut supra et mihi Notario pro eo stipulanti ut supra vel cui mandabit seu ordinabit prefatus D. Arvarus (sic) scilicet ad appotecas ipsorum magistrorum et hoc infra et per totum mensem Septembris proxime venturum anni presentis et de quibus laboreriis predictis continetur in dessigno tradito per dictum Martinum dicto nomine dictis mag. Iohanni Iacobo et Iohanni Petro in presentia mei Notarii et testium infrascriptorum [...] quod dessignum fuit subscriptum per ipsum Martinum ac vissum et subscriptum per me Notarium infrascriptum et quod dessignum ipsi mag. Iohannes Iacobus et Iohannes Petrus representare promittunt semper ad omnen requisitionem ipsius Martini dicto nomine seu prefati D. Alvario vel allii pro eo omni exceptione remotta. Ex adverso dictus Martinus dicto nomine presens et acceptans predicta sponte et ex ipsius certa scientia promissit et promittit dictis mag. Iohanni Iacobo et

${ }^{71}$ La parte correspondiente al convento del Sancti Spiritus fue destruida igualmente en el siglo XIX y el palacio de los Fernández de Córdoba en 1919 (Barrios Rozúa ob.cit. p.293). 
Iohanni petro presentibus et acceptantibus ab eis recipere dicta marmora nomine emptionis et eis solvere pretium eorum ad rationes infrascriptas scilicet balaustros ad rationem soldorum viginti novem monete Ianue pro singulo balaustro et cornises ad rationem soldorum viginti Ianua pro singulo parmo una pro allia et pillas pro ambabus scuta triginta quinque auri Solis et quas pecunias predicti pretii et ad rationes predictas dictus Martinus suo propio nomine se abligando dare et solere promissit et promitttit dictis mag. Iohanni Iacobo et Iohanni Petro presentibus et acceptantibus ut supra vel persona pro eis legitime in hunc modum scilicet ex nunc scuta quinquaginta auri Solis que dicti Iohannes Iacobus et Iohannes Petrus sponte etc. fatentur habuisse et recepisse a dicto Martino presenti et acceptanti de quibus infra satisfacionem dictorum laboreriorum se bene solutos quietos et contentos vocaverunt et vocant et totidem scuta quinquaginta ipse martinus eis solvere promissit infra dies quindecim proxime venturos et scuta centum auri solis eis solvere promissit ut supra facta dimida dicte opere seu dictorum laboreriorum et totum ressiduum seu complementum dicti pretii ad rationes predictas in consignacione dicte opere usque ad integram solucionem precii [...] quod dictus Martinus dictonomine seu dictus D. Alvarus debeat dimittere hic in Ianua ipsis Magistris unum civem Ianue qui eis solvat dictas pecunias restantes ad habendum occasione pretii dicte opere eis modis et formis quibus supra et sic est per pactum etc. [...] quod si dicti magistri Johannes Jacobus et Johannes Petrus, non fecerint intra dictum tempus, quod talli casu, liceat et licitum sit dicto martino, dicto nomine, presenti et acceptanti et stipulanti, facere per allios magistros eorum propriis expensis et in bonis ipsorum magistri Joannis jacobi et Johannis Petri, contradicendo magistro Johanni jacobo et Johanni Petro, suis terminis si occurrerit in omnibus, sine soluptionem dictam de peccuniis solucionis ut supra quod, talli casu per [Ill.D. Alvarum ? roto en el original] a termino quod [?] solucionis ut supra, nec habendis peccuniis, quod intelligatur et sit prolongatum eius tempus perfectionis et consignationis dictorum laboreriorum fiendi ut supra, quia ipsi magistri, sine peccuniis, non possunt laborare [...] etc. quod dicti magistri Johannes Jacobu et Johannes Petrus in solidum, intelligantur, nec sint obligati quoad confectionem et consignationem dictarum pillarum intra dictum tempus nec dictus Martinus ad soluptionem pretii, nixi si dictus dominus Alvarius eis per eius appodisiam, prolunget tempus consignationis carum opperarum per totum mensem octobris proxime venturum [...] Actum Ianue [...] Anno millesimo quingentessimo trigesimo sexto. [...] die Mercurri XVIII Jullii [...] + Die ea hora et loco suprascriptis [...] Dicti mag. Iohannes Iacobus et Iohannes Petrus in solidum ex una parte attentis predictis laboreiis promittunt [...]consignare ipsi Martino fontanetam unam marmari cum suo pede et bacille ac cum pigna superius quam ipse mag. Iohannes Iacobus dicti habere in sua appoteca et que fuit in laborerio viridarii q.Martini Centurioni et hoc ad omnem requisicionem ipsius Martini [...] (Archivio di Stato di Genova Not. Stefano Sauli Carrega sc.226 f.9 doc. 430)

Doc. $\mathbf{n}^{\mathbf{0}}$ 2. +1536 die Sabati V Augusti [...]Dictu mag. Iohannes Iacobus de la Porta [...] acceptat in socios et pro soccios in sua dimidia suprascripte opere seu laboreriorum suprascriptorum modis formis pactis et preciis suprascriptis mag. Nicolaum de Curte presentem et acceptantem ac Guglielmum de la Porta filium ipsius mag. Iohannis Iacobi absentem [...] Et qui mag. Nicolaus fatetur habuisse et recepisse a dicto mag.l Iohanne Iacobo presenti et acceptanti etc: scuta octo et unum tercium alterius auri Solis in pecunia numerata in presentia etc. et sunt pro tercia parte scutorum vigintiquinque auri solis perventorum in ipsum mag. Iohannem Iacobum ex suprascripta opera [...] (A.S.G. Not. Stefano Sauli Carrega. sc. 226 f.9 doc. 430)

Doc. $\mathbf{n}^{\circ}$ 3. +1536 die Vii Octobris[...] Dicti magistri Johannes Jacobus et Johannes Petrus sponte, etc.fatentur habuisse et recepisse a Baptista de Promentorio de Ferrariis quondam Christoffori, presenti et acceptanti libras ducentas septuagintaquinque et soldos tresdecim Janue, in peccunia numnerata, eisdem traditas et numeratas in prsentia, etc. et sunt pro dicto Ill. D.Alvaro, absenti et me notario, etc. infra solucionem suprascripte opperis marmore, de qua in suprascripto instrumento fit mentio, cui relatio habeatur [...] . [25-1-1537] +1537 die iovis XXV ianuarii [...] Dicti mag. Johannes jacobus de la Porta et Johannes Antonius de Pasallo fillius dicti magistri Johannis Petri, absentis, [...] fatentur habuisse et recepisse ultra suprascripta a dicto Baptista de Prementorio de Ferrariis q. Christoffori, presenti et acceptanti, etc. libras centum quinquagintaunam cum dimidia Janue, in 
peccunia nunmerata in presentis, etc.l et sunt pro deicto Ill. D. Alvaro, absente et me notario etc. ad complementum et pro complemento librarum 665 Janue computatis omnibus suprascriptis partitis ac etiam computatis omnibus alliis peccunis habitis per dictos mag. Johannem Jacobum et Johannem Petrum, occasione dicte opperis tam cum appodisiis et instrumentis quam sine usque in hodiernum et sunt infra solucionem dicte opperis marmoree de qua in suprascripto instrumento fit mentio, cui habeatur relatio [...] in formam et quam opperam perfectam in omnibus iuxta formam instrumenti dictorum mag. Johannes Jacobus et Jo. Antonius, dicto nomine promittunt dare et consignare dicto Baptiste, dicto nomine, presenti, etc. infra festum Pasce Resurrectionis proxime venturum, sub pensa scutorum 25 auri solis, in quam incurrant dicti magistri in casu inobservatie applicata dicto Baptiste, dicto nomine, pro suo iusto dammno et intereae et quam opperam promittit dictus Baptista, dicto nomine, recipere quando fiet perfecta intra dictum tempus et suum ressiduum pretii solvere dictis Magistris in omnibus, iuxta formam supradicti instrumenti, cui habeatur relatio [...] (A.S.G. Not. Stefano Sauli Carrega. sc. 226 f.9 doc. 430. No publicado por Alizeri)

Doc. no 4. "[...] Mag. Nicolaus de Curte sculptor Francisci major annis vigintiquinque et qui palam et publice negociatur ut ipse mag. Nicolaus presens dicit et fatetur et mag. antonius de Semino pictor q. Andree [...] confitentur habuisse et recepisse a Baptista de Promontorio de Ferrariis q. D. Christofori cive Ianue presenti et acceptanti nomine Ill.D. Alvari de Basan absentis et me notario pro eo stipulante etc. scuta octuaginta unum auri Imperatoris in peccunia numerata eisdem mag. Nicolao et mag. Antonio tradita et numerata per dictum Baptistam dicto nomine in peccunia numerata in presentia mei notarii et testium infrascriptorum ad hec specialiter vocatorum et rogatorum ex quibus dictus mag. Nicolaus habuit scuta triginta unum et dictur mag. Antonius scuta quinquaginta facientia dictam summan scutorum octuaginta unius et de quibus dict mag. Nicolaus et mag. Antonius respective ut supra se bene quietos et contentos voccaverunt et voccant (sic) a dicto Baptista dicto nomine presente et acceptante prout supra et me notario ut supra stipulante etc. Et propterea dicti mag. Nicolaus et Mag. antonius sponte et ex ipsorum certa scientia ut supra promisserunt dicto Baptiste dicto nomine presente et acceptanti prout supra et mihi jam notario prout supra stipulanti recedere de presenti civitate Ianue et accedere cum navi patronizata per Iohannem Danda ad presens existenti in portu Ianue in presente viagio ad partes Hispanie et ex Hispania accedere et se transferre ad locum Granate seu ad alia loca ad que dixerit et voluerit dictus D.D. Alvaro in cujusdam D.D.Alvari laboreriis secundum et aprout se accordabuntur cum dictoD. Alvaro et juxta eorum acccordium sibi D. alvaro acceptare et compensare in eorum salariis dicta scuta octuaginta unum auri Imperatoris de quibus supra scilicet quiliber eorum pro sua ratta (sic) onmi exceptione remotta declarato tamen quod salarium ipsorum magistrorum Nicolai et Antonii incipiat et sic incipere intelligatur a die qua dicti mag. Nicolaus et Mag. Antonius recedent de portu Ianue cum dicta navi pro edictis partibus Hispanie ut supra quia sic contentatur et consentit et affirmat dictus Baptista dicto nomine [...] Actum Ianue [...] millesimo quingentesimo trigesimo septimo [...] vigesima nona Ianuarii [...] + +1537 die Mercurii XIIII Februari: Dictus mag. Nicolaus de Curte[...]fatetur habuisse et recepisse a dicto Baptista de Promontorio de Ferrariis de numerato occasione de qua supra et in omnibus ut supra facientia complementum scutorum quinquaginta computatis suprascriptis scutis triginta uno ut supra habitis per ipsum Nicolaum in omnibus ut in suprascripto instrumento continetur cui habeatur relacio: et de ipsis scutis decem et novem auri Imperatoris de numerato ut supra et in omnibus prout supra dictus mag. nicolaus se bene quietum tacitum contentum [...] (A.S.G. Not. S. Sauli Carrega. Fogliaz.10, no 2016 doc.409) 